\title{
Structural features of bionanocomposite derived from novel designed poly(ester-imide) based on natural amino acids with hydroxyl segments tailored for better dispersion of $\mathrm{TiO}_{2}$ nanofiller
}

\author{
SHADPOUR MALLAKPOUR ${ }^{1,2, *}$ and PARVIN ASADI ${ }^{1}$ \\ ${ }^{1}$ Organic Polymer Chemistry Research Laboratory, Department of Chemistry, Isfahan University of Technology, Isfahan \\ 84156-83111, I. R. Iran \\ ${ }^{2}$ Nanotechnology and Advanced Materials Institute, Isfahan University of Technology, Isfahan 84156-83111, I. R. Iran
}

MS received 19 January 2012; revised 19 May 2012

\begin{abstract}
Deliberately inorganic nanoparticles (NP)s in polymer matrices significantly affect their characteristics and therefore their applications, but key factor to achieve the expected efficiency is well dispersion of the NPs in polymer matrix. The work presented here deals with the polymerization of amino acid-based monomer to synthesize optically active poly(ester-imide) (PEI) with hydroxyl terminated groups, using tosyl chloride/pyridine/ $N, N$ dimethylformamide system as a condensing agent. The synthesized polymer was used for the preparation of bionanocomposite (BNC) containing modified titanium dioxide $\left(\mathrm{TiO}_{2}\right)$ NPs using ultrasonic irradiation. With the aim of $\gamma$-amidopropyl-triethoxylsilicane as a coupling agent, the surface of nanoscale $\mathrm{TiO}_{2}$ was modified to decrease aggregation of the NPs in polymer matrix. The obtained PEI/TiO $\mathrm{BNCs}_{2} \quad \mathrm{BN}$ were characterized with fourier transfer infrared (FT-IR), thermogravimetric analysis, field emission scanning electron microscopy (FE-SEM), X-ray diffraction and transmission electron microscopy (TEM) techniques. Morphology study of resulting $\mathrm{PEI} \mathrm{TiO} \mathrm{BNCs}_{2}$ by FE-SEM and TEM analyses demonstrated that the hydroxyl-terminated polymer chains reduced aggregation of the NPs and thus lead to better dispersion of the NPs in the polymer matrix.
\end{abstract}

Keywords. $\quad \mathrm{TiO}_{2}$ nanoparticles; bionanocomposite polymer; ultrasonic irradiation; amino acids.

\section{Introduction}

Recently, a great deal of research about nanoscale-filled polymer composites give a new way to prepare material which not only have combined the advantageous properties of metals and polymers, but also exhibit many new characters (Caseri 2000). Because of their unique properties, these materials have wide spread potential applications (Srivastava et al 2008). There are different methods for incorporating nanoparticles (NP)s in polymer matrix, which in, bonding of NPs in inorganic and organic phases can be covalently or non-covalently (Kong et al 2002; Lee et al 2007; Ghanshyam and Puyam 2009; Mejia et al 2010), but the most important factor to consider in deciding between different processing techniques, is the requirement of good dispersion of the NPs in the polymer matrix. Dispersion of the NPs plays a major role in the property such as thermal, mechanical, optical and electrical properties (Ray et al 2007; Koha et al 2008; Ali and Mohan 2010; Bhatta et al 2011). This request has recently led to far-reaching efforts to explore different method for obtaining good spreading of nanofiller. The NPs have superior advantages with comparison of bulk

*Author for correspondence (mallak@cc.iut.ac.ir; mallak777@yahoo.com; mallakpour84@alumni.ufl.edu) material that they originate from. Several factors such as shape, dimension, size, aggregate degree, dispersibility and concentration can greatly influence on the effectiveness of these materials (Tomoda et al 2008; Narayan et al 2009; Joon-Ho et al 2011). Some of the typical physicochemical characteristics of the NP, with emphasis on sizedependent phenomena are high surface-to-volume (S/V) ratio, depressed melting temperature, discrete electronic structure and high reactivity (Valueva et al 2010). Among different NPs, $\mathrm{TiO}_{2}$ has received great annual world consumption due to its strong oxidizing power of the photogenerated holes, chemical inertness, non-toxicity, low cost, high refractive index and other advantageous surface properties. Rutile and anatase are mostly manufactured the structure of $\mathrm{TiO}_{2}$ in chemical industry as microcrystalline materials. Thermodynamic calculations show that rutile is the most stable phase at all temperatures and pressures. $\mathrm{TiO}_{2}$ has received a great amount of requests because of its application as a white pigment in paints, plastics, paper and cosmetic products and also for the use as photocatalyst, catalyst support or promoter, as gas sensor, as in electric and electrochromic devices and so on (Linsebigler et al 1995; Tyan et al 1999; Yang et al 2005; Bae et al 2006; Liaw and Chen 2007; Tsai et al 2008; Buzarovska et al 2009; Tryba et al 2009). The nanostructure of $\mathrm{TiO}_{2}$ inorganic particles in polymer matrix are responsible for the observed 
multifunctional characteristics, but as mentioned above, one of the main concerns that affect its expected efficiency and application is well dispersion of $\mathrm{TiO}_{2}$ NPs. In nanocomposites made by direct mixing, the interactions between the hosting matrix and the entrapped $\mathrm{TiO}_{2}$ are relatively weak; therefore the aggregation of nano- $\mathrm{TiO}_{2}$ particles stemming from their high surface energy is a perennial problem. One approach aiming at solving this problem is breaking down the agglomerated NPs with ultrasonic irradiation. Ultrasound radiation technique has been explored as a very attractive and alternative tool for preparation of various nanosized materials, such as carbides, oxides, sulfides and composite NPs (Feng et al 2002; Wang et al 2007; Chen et al 2008; Li and Wang 2010). Ultrasound radiation by producing localized hot spots with an exceedingly high transient temperature $(5000 \mathrm{~K})$, pressure $(1800 \mathrm{~atm})$ and cooling rate $(1010 \mathrm{~K} / \mathrm{s})$ can help the chemical effect to occur. However, this approach is caused by the limited interaction between the inorganic fillers and the organic matrix, relative to the very strong interaction between individual NPs. An improved way is modifying the surface of the inorganic filler and covalent attachment to polymer chains which play down agglomeration and fortify the interaction between the nanofiller and polymer matrix (Yu et al 2003; Chen et al 2007; Sow et al 2011).

Synthesis of optically-active polymers is an important field in macromolecular science because they have a wide variety of potential applications based on the chiral structure. The existence of asymmetric centres along polymeric chains awards macromolecules special structural and physical properties (Cornelissen et al 2001; Itsuno 2005). A large number of studies on chiral materials, reported in literature, are by far devoted to amino acids which would lead to the creation of chiral centre into polymers. The selection of amino acids is due to their accessibility with high optical purity and lower cost. The presence of amino acid in the polymer chains as a chiral group is very useful for the pharmaceutical industry for enantio-selective separation of drugs. Additionally, biocompatibility requirements may be satisfied through the use of amino acids in polymer which are used in dentistry, drug delivery, gene therapy, tissue engineering, etc. On the other hand, many amino acids as multi-functional natural metabolites are biologically active to produce biodegradable polymers (Mallakpour and Dinari 2010, 2011; Mallakpour and Zadehnazari 2011; Zhang and Huang 2011).

Polyimides are gaining wide acceptance due to their valuable complex of toughness, insulating coatings and high thermal and oxidative resistance. Beside these advantages, molecular stiffness, high polarity and high intermolecular association forces make these polymers virtually insoluble in any organic medium, and shift the transition temperatures to well above the decomposition temperatures; therefore they still lack certain optimum possessions for mechanical properties (Liaw and Liaw 2001; Yu et al 2004). One approach to rise above this drawback involves the synthesis of copolyimides such as poly(ester-imide)s (PEI)s and poly(amideimide)s by incorporating amide or ester functionality at regular intervals in the polyimide chains (Mallakpour and Khani 2007; Mallakpour and Asadi 2010). Direct polycondensation using condensing agent is an useful procedure for the synthesis of polyamides, polyesters and other copolymers. Higashi et al (1999) reported that Vilsmeier adduct derived from arylsulfonyl chlorides and $\mathrm{N}, \mathrm{N}$ dimethylformamide (DMF) in pyridine (Py) was successfully used as a suitable condensing agent for the synthesis of aromatic polyesters (Higashi et al 1999).

In our previous study, we synthesized an optically active PEI via reaction of chiral 5-(2-phthalimidyl-3methylbutanoylamino)isophthalic acid (1) as a diacid and also $N, N^{\prime}$-(pyromellitoyl)-bis-L-tyrosine dimethyl ester (2) as a phenolic diol and then synthesized polymer was subjected for the preparation of bionanocomposites (BNC)s containing $\mathrm{TiO}_{2}$ NPs (Mallakpour and Asadi 2012). The objective of this presentation is to synthesize and characterize the novel designed optically active PEI end-capped with hydroxyl group. To this purpose, the previous synthesized polymer chains were selectively end-capped with hydroxyl end groups to achieve better interaction with modified $\mathrm{TiO}_{2}$ in the synthesis of BNC. $\gamma$-amidopropyl-triethoxylsilicane (KH550) as a coupling agent was utilized to modify the surface properties of $\mathrm{TiO}_{2}$ and also ultrasonic was taken up to simulate good dispersibility of modified $\mathrm{TiO}_{2}$ in polymer matrix. Finally the PEI and obtained BNCs were subjected for Fourier transfer infrared (FT-IR) spectroscopy, X-ray diffraction (XRD) and thermogravimetry analysis (TGA) techniques. The morphology of the prepared materials was examined by field emission scanning electron microscopy (FE-SEM) and transmission electron microscopy (TEM) techniques. The results show better dispersion and lower size of $\mathrm{TiO}_{2}$ NPs in PEI matrix.

\section{Experimental}

\subsection{Materials}

Solvents and chemicals were obtained from the Merck Chemical Co. (Germany) and Aldrich Chemical Co. (Milwaukee, WI, USA). The amino acids of synthetic grade were used as received without further purification. $N, N$-dimethylacetamide (DMAc), DMF, Py, $N$-methyl-2pyrrolidone (NMP) and triethylamine (TEA) were dried over barium oxide $(\mathrm{BaO})$ and then distilled under reduced pressure. Pyromellitic dianhydride was purified by recrystallization from a mixture of acetic anhydride and acetic acid (1:4). 5-aminoisophthalic acid was recrystallized from $\mathrm{H}_{2} \mathrm{O} / \mathrm{DMF}$ (4/1) mixture. A commercial form of $\mathrm{TiO}_{2}$ with average size about 35-50 nm was obtained from nanosabz Co.

\subsection{Techniques}

Structural confirmation of PEI was done by proton nuclear magnetic resonance $\left({ }^{1} \mathrm{H}-\mathrm{NMR}, 500 \mathrm{MHz}\right)$ spectra recorded in dimethylsulfoxide (DMSO)- $d_{6}$ solution using a Bruker Advance 500 instrument (Bruker, Germany) and FT-IR 
spectra were also recorded on spectrophotometer (Jasco-680, Japan). The spectra of solids were obtained using KBr pellets. The vibrational transition frequencies are reported in wavenumbers $\left(\mathrm{cm}^{-1}\right)$. Band intensities are assigned as weak (w), medium (m), strong (s) and broad (br). Inherent viscosities were measured by using a Cannon-Fenske routine viscometer (Germany) at the concentration of $0.5 \mathrm{~g} \mathrm{dL}^{-1}$ in $\mathrm{DMF}$ at $25{ }^{\circ} \mathrm{C}$. Specific rotations were measured by a Jasco polarimeter (Japan). Preparation of $\mathrm{PEI} / \mathrm{TiO}_{2} \mathrm{BNCs}$ was occurred on a MISONIX ultrasonic XL-2000 SERIES. Ultrasonic irradiation was carried out with the probe of an ultrasonic horn immersed directly in the mixture solution system with frequency $2 \cdot 25 \times 104 \mathrm{~Hz}$ and power $100 \mathrm{~W}$. Optical absorption spectra (UV-Vis) of the $\mathrm{PEI} / \mathrm{TiO}_{2} \mathrm{BNCs}$ were measured at room temperature by JASCO V-750 UV-Vis/NIR spectrophotometer using solid pellets. FESEM measurement of $\mathrm{PEI} / \mathrm{TiO}_{2}$ BNCs was carried out on a HITACHI S-4160. TEM measurements were performed on a Philips CM120 instrument, operated at an accelerating voltage of $100 \mathrm{kV}$. TGA data for polymer and $\mathrm{PEI} / \mathrm{TiO}_{2} \mathrm{BNCs}$ were taken on STA503 WinTA instrument at a heating rate of $10{ }^{\circ} \mathrm{C} \min ^{-1}$ under nitrogen $\left(\mathrm{N}_{2}\right)$ atmosphere. The XRD patterns were recorded by employing a Philips X'PERT MPD diffractometer $\mathrm{Cu} K \alpha$ radiation: $\lambda=0.154056 \mathrm{~nm}$ at $40 \mathrm{kV}$ and $30 \mathrm{~mA}$ over the $2 \theta$ range of $10-80^{\circ}$ at a scan rate of $0 \cdot 05^{\circ} / \mathrm{min}$.

\subsection{Monomer synthesis}

Optically active monomers, 5-(2-phthalimidyl-3methylbutanoylamino)isophthalic acid (i) as a diacid and also $N, N^{\prime}$-(pyromellitoyl)-bis-L-tyrosine dimethyl ester and (ii) as a phenolic diol, were prepared according to our previous work (Mallakpour and Asadi 2010).

\subsection{Polymer synthesis}

The hydroxyl end-capped PEI was prepared by the following procedure: A Py $(0.20 \mathrm{~mL})$ solution of tosyl chloride $(\mathrm{TsCl}$; $\left.0.37 \mathrm{~g} ; 1.94 \times 10^{-3} \mathrm{~mol}\right)$, after $30 \mathrm{~min}$ stirring at room temperature, was treated with $\operatorname{DMF}\left(0.14 \mathrm{~mL} ; 1.94 \times 10^{-3} \mathrm{~mol}\right)$ for $30 \mathrm{~min}$ and the resulting solution was added dropwise to a solution of diacid (1) $\left(0.10 \mathrm{~g} ; 2.44 \times 10^{-4} \mathrm{~mol}\right)$ in Py $(0.20 \mathrm{~mL})$. The mixture was maintained at room temperature for $30 \mathrm{~min}$ and then stoichiometric amount of diol $2(0.14 \mathrm{~g}$; $\left.2.44 \times 10^{-4} \mathrm{~mol}\right)$ was added to this mixture and the whole solution was stirred at room temperature for $30 \mathrm{~min}$. A slight excess $(2 \% \mathrm{wt})$ of aromatic diol was then added in order to produce hydroxyl chain ends and then the mixture were heated at $120{ }^{\circ} \mathrm{C}$ for $4 \mathrm{~h}$. The viscous solution was poured into $20 \mathrm{~mL}$ of methanol and the precipitated solid was filtered off and dried at $80{ }^{\circ} \mathrm{C}$ for $6 \mathrm{~h}$ under vacuum to yield $80 \%$ of the solid PEI. The inherent viscosity of the resulting PEI was obtained $0.30 \mathrm{dL} / \mathrm{g}$ and the specific rotation was measured $\left([\alpha]_{D}^{25}=-17 \cdot 8\right.$, measured at a concentration of $0.5 \mathrm{~g} / \mathrm{dL}$ in DMF at $25^{\circ} \mathrm{C}$ ). Hydroxyl end-capped polymer was employed as the matrix for the synthesis of BNCs.
Hydroxyl end-capped PEI: FT-IR peaks (KBr): 3419 (m, br), 2954 (m), 1778 (m), 1724 (s), 1678 (m), 1548 (w), 1505 (m), 1452 (m), 1382 (m), 1364 (s), 1215 (m), 1184 (w), 1167 (m), 1112 (m), 1018 (m), 917 (w, br), 887 (w), 833 (w), $712(\mathrm{w}), 633(\mathrm{w}),\left(\mathrm{cm}^{-1}\right)$.

${ }^{1} \mathrm{H}-\mathrm{NMR}\left(500 \mathrm{MHz}, \mathrm{DMSO}-d_{6}\right): \delta 0.81\left(\mathrm{CH}_{3}\right), 0.98$ $\left(\mathrm{CH}_{3}\right), 2.70(\mathrm{CH}), 3.32\left(\mathrm{CH}_{2}\right), 3.67\left(\mathrm{OCH}_{3}\right), 4.54(\mathrm{CH}$, chiral centre), $5.32(\mathrm{CH}$, chiral centre), 6.90 (4H aromatic), 7.24 (4H aromatic), 7.87 (4H aromatic), 8.48 (3H aromatic), 8.58 (2H aromatic), $9.13(\mathrm{OH}$, end group), 10.35 $(\mathrm{NH}),(\mathrm{ppm})$. Elemental analysis calculated for $\mathrm{C}_{82} \mathrm{H}_{64} \mathrm{~N}_{6} \mathrm{O}_{25}$ (1532.14 g/mol): C, 64.90\%; H, 4.17\%; N, 5.48\%. Found: C, $63.5 \%$; H, $4.38 \%$; N, $5.93 \%$.

\subsection{Surface modification of $\mathrm{TiO}_{2}$}

Before the reaction of $\mathrm{TiO}_{2}$ with synthesized polymer, the NPs were dried at $500{ }^{\circ} \mathrm{C}$ for about $7 \mathrm{~h}$ to remove the water absorbed on the surface. Because of direct mixing of NPs, rough aggregation was caused in polymer matrix, KH550 was used as a coupling agent to modify the surface of $\mathrm{TiO}_{2} \mathrm{NPs}$ and reduce their aggregations. For this purpose $0.30 \mathrm{~g}$ of the dried $\mathrm{TiO}_{2}$ were dispersed in $10 \mathrm{~mL}$ of acetone for $3 \mathrm{~min}$ with the titanium sonic probe immersed directly in the solution for $30 \mathrm{~min}$ and then according to literature (Mallakpour and Asadi 2012), $10 \%$ wt of $\mathrm{TiO}_{2}$ NPs, KH550 (0.30 mL) was dissolved in $10 \mathrm{~mL}$ of distilled water and was added to the mixture under ultrasonic irradiation. The whole blend was centrifuged for $30 \mathrm{~min}$ and the precipitate was washed twice with ethanol and distilled water, respectively, to remove the residual KH550 completely and then dried in vacuum at $60{ }^{\circ} \mathrm{C}$ for $4 \mathrm{~h}$. The presence of organic groups on the surface of modified NPs was confirmed by FT-IR spectrum.

\subsection{Preparation of $\mathrm{PEI} / \mathrm{TiO}_{2} \mathrm{BNCs}$}

BNCs were fabricated through solution mixing of $0.10 \mathrm{~g}$ of dried PEI and the appropriate amounts of modified $\mathrm{TiO}_{2}$ ( 5 and $10 \%$ wt of PEI) into $10 \mathrm{~mL}$ of absolute ethanol. The reactions occurred by ultrasonic irradiation for $4 \mathrm{~h}$ at $30{ }^{\circ} \mathrm{C}$. Then the mixtures were centrifuged for $10 \mathrm{~min}$ and washed with ethanol and distilled water, respectively. Finally the obtained products as $\mathrm{PEI} / \mathrm{TiO}_{2} \mathrm{BNCs}$ were dried in vacuum at $80{ }^{\circ} \mathrm{C}$ for $6 \mathrm{~h}$ and kept for further characterizations.

\section{Results and discussion}

\subsection{Synthesis of monomers}

For the synthesis of diacid, firstly, phthalic anhydride reacted with stoichiometric amount of S-valine, in reflux acetic acid and corresponding imide acid was synthesized which was reacted with thionyl chloride in dichloromethane to obtain diacid chloride. From the reaction of diacid chloride with 
5-amino isophthalic acid in dry DMAc in the presence of TEA, diacid compound 1 was achieved. For the preparation of $N, N^{\prime}$-(pyromellitic diimido)-bis-L-tyrosine dimethyl ester 2 as a diol, L-tyrosine was added to a methanol solution containing thionyl chloride and stirred at room temperature to obtain white, powdery, L-tyrosine methyl ester hydrochloride which was deprotonated with TEA in $\mathrm{CH}_{2} \mathrm{Cl}_{2}$ to obtain L-tyrosine methyl ester. Achieved compound was reacted with pyromellitic dianhydride in reflux DMF so that yellow precipitate was collected in a mixture of $100 \mathrm{~mL} / 5 \mathrm{~mL}$ of cold water/concentrated $\mathrm{HCl}$ as a diol 2.

\subsection{Polymer synthesis}

With the aim of Vilsmeier adduct as a condensing agent, polycondensation of aromatic diacid (1) and slight excess ( $2 \% \mathrm{wt}$ ) of diol 2 was performed to obtain chiral hydroxyl end capped PEI (scheme 1). To this point, $\mathrm{TsCl}$ was dissolved in Py to yield sulfonium salt and after a certain period of time (aging time) the solution was treated with DMF for $30 \mathrm{~min}$ to form Vilsmeier adduct. The reaction mixture was added to a solution of diacid 1 in Py to form activated acid. After that, powder of diol 2 was added and the whole solution was heated for a period of time. The inherent viscosity of the synthesized PEI was $0.30 \mathrm{dL} / \mathrm{g}$ and the yield was $80 \%$. The specific rotation of this polymer is $[\alpha]_{D}^{25}=-17.4(0.05 \mathrm{~g}$ in $10 \mathrm{~mL}$ of DMF) which shows that, the polymer is optically active and chirality was introduced into the backbone of the polymer via amino acid linkages. Due to the presence of bulky group in side chain, which prevents the packing of the macromolecules and facilitates the diffusion of solvent molecules among the polymer chains, synthesized polymer is soluble in organic polar solvents such as DMAc, DMF, NMP and in sulfuric acid at room temperature. It is insoluble in solvents such as chloroform, methylene chloride, acetone, cyclohexane, tetrahydrofuran and water.

\subsection{Characterization of polymer}

Characteristic bands of synthesized PEI were confirmed by means of FT-IR. This spectrum showed a broad absorption around $3419 \mathrm{~cm}^{-1}$ which is corresponded to amide $\mathrm{N}-\mathrm{H}$ and hydroxyl. Presence of different carbonyl groups in the polymer chains were confirmed with the peaks at $1778(\mathrm{C}=\mathrm{O}$ imide group), $1721 \mathrm{~cm}^{-1}$ (C=O ester group) and $1605 \mathrm{~cm}^{-1}$ ( $\mathrm{C}=\mathrm{O}$ amide group). The absorption bands appeared around $3013-3100$ and $2850-2930 \mathrm{~cm}^{-1}$ are related to the corresponding aromatic and aliphatic $\mathrm{C}-\mathrm{H}$ stretching vibration, respectively. This PEI exhibited absorptions at 1382 and $725 \mathrm{~cm}^{-1}$ which showed the presence of the imide heterocycle in this polymer.

The ${ }^{1} \mathrm{H}-\mathrm{NMR}(500 \mathrm{MHz})$ spectrum of PEI is shown in figure 1. In spectrum of PEI, the protons of the chiral centres for S-valin and L-tyrosine appeared at 4.54 and $5.32 \mathrm{ppm}$, respectively. Appearances of the methoxy $\left(\mathrm{O}-\mathrm{CH}_{3}\right)$ protons at $3.68 \mathrm{ppm}$ as a single peak indicate the presence of ester group in the polymer's side chain. The absorption of $\mathrm{CH}_{2}$ of diol appeared at $3.35 \mathrm{ppm}$. The peak of the $\mathrm{C}-\mathrm{H}$ isopropyl group of S-valine showed at $2.70 \mathrm{ppm}$ and the absorptions of the dia-stereotopic $\mathrm{CH}_{3}$ proton groups of $\mathrm{S}$-valine appeared at 0.81 and $0.98 \mathrm{ppm}$. The absorption of aromatic protons was emerged in the range of 6.90-8.58 ppm. The appearance of the $\mathrm{N}-\mathrm{H}$ proton of amide group around the $10.30 \mathrm{ppm}$ indicates the presence of amide group in the polymer's chain. Peak appeared at $9.13 \mathrm{ppm}$ pointed the presence of phenolic protons of the end groups of the PEI. The elemental analyses result for PEI is also in agreement with calculated values of carbon, hydrogen and nitrogen in the polymer.

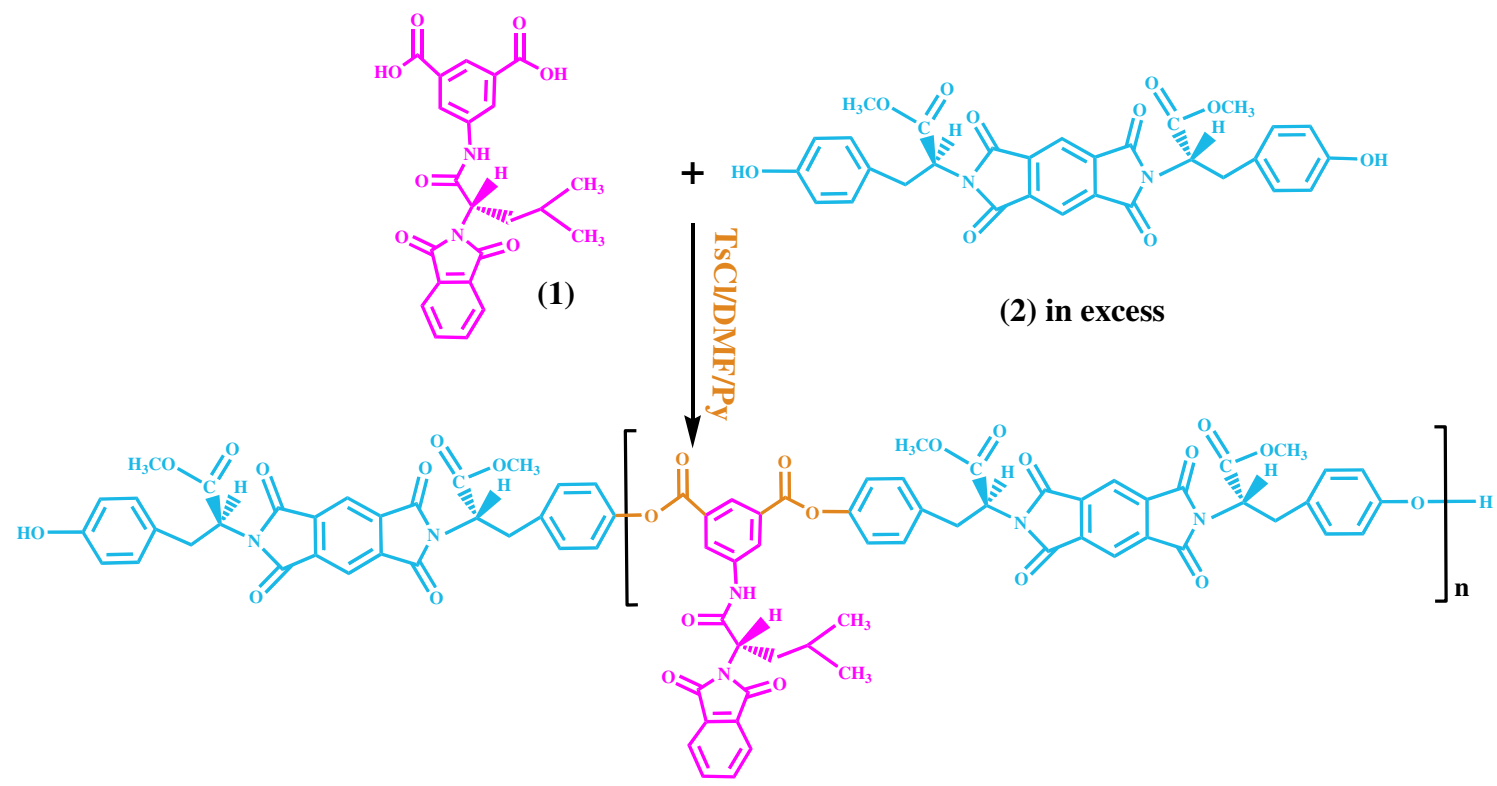

Scheme 1. Synthesis of hydroxyl end-capped PEI. 


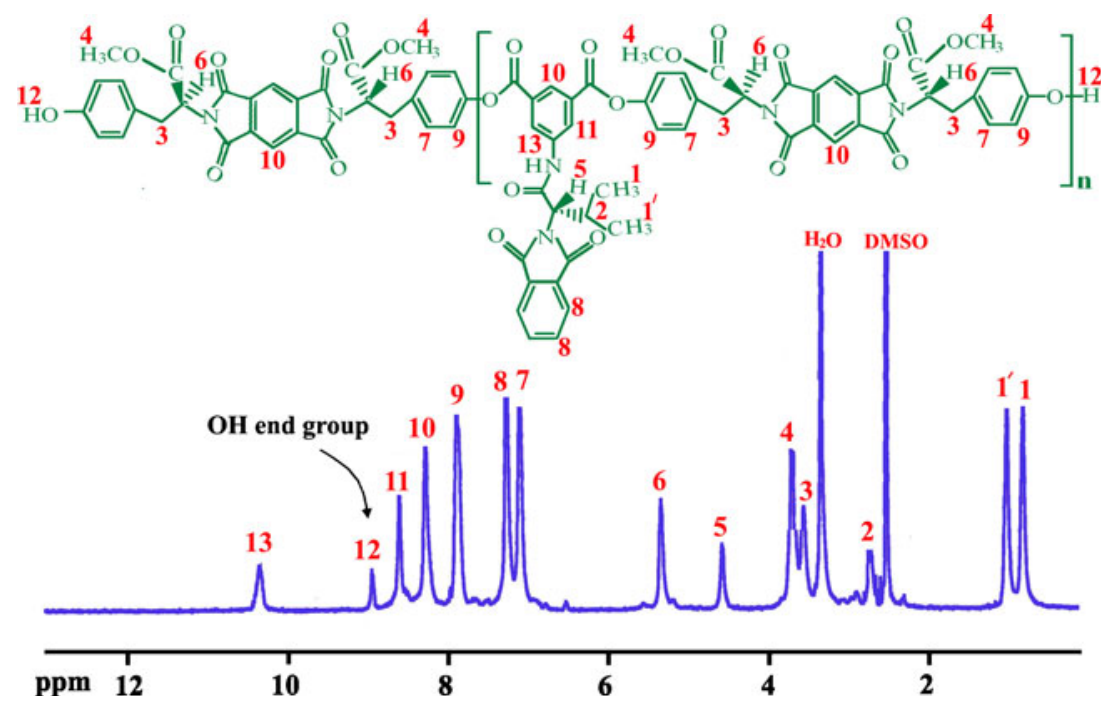

Figure 1. ${ }^{1} \mathrm{H}-\mathrm{NMR}(500 \mathrm{MHz})$ spectrum of hydroxyl end-capped PEI in DMSO- $d_{6}$ at RT.

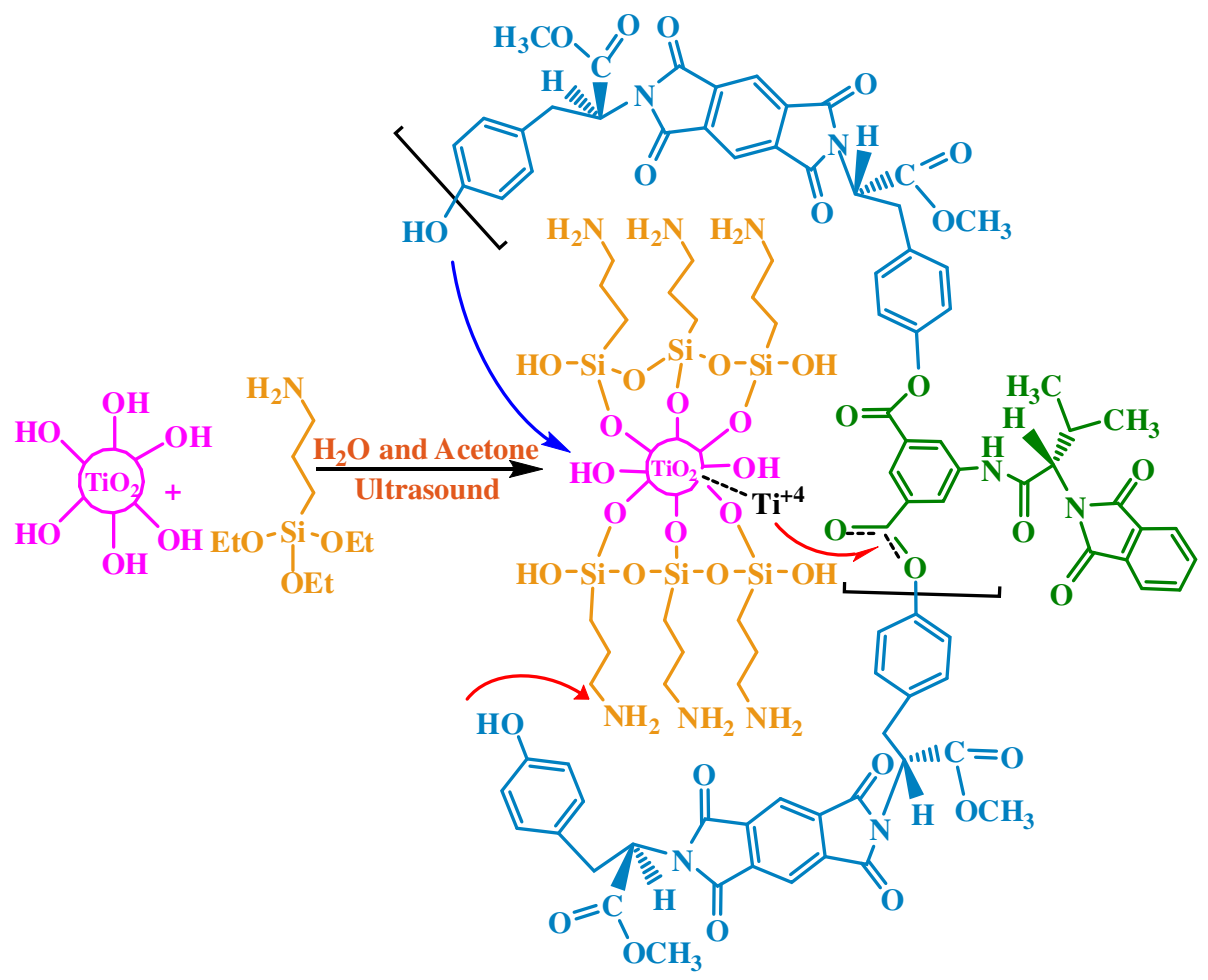

Scheme 2. Modifying $\mathrm{TiO}_{2}$ NPs with $\mathrm{KH} 550$ and their interactions with hydroxyl end-capped PEI.

\subsection{Surface modification of $\mathrm{TiO}_{2}$ and preparation of $\mathrm{PEI} / \mathrm{TiO} \mathrm{O}_{2} \mathrm{BNCS}$}

Due to inorganic nature, $\mathrm{TiO}_{2}$ NPs will be aggregated inadequately in polymer matrix and cause size to be extended up to few micrometers. In this work coupling agent by its hydrophilic end react with the surface $\mathrm{OH}$ groups on NPs and play a major role in good dispersity of the NP in polymer matrix (scheme 2). When KH550 was transferred to the water, ethoxy groups were hydrolyzed and sol-gel took place to form $\mathrm{Si}-\mathrm{O}-\mathrm{Si}$ bonds. Then, by reaction with hydroxyl groups of $\mathrm{TiO}_{2}$, the alkyl groups of coupling agent were placed on the surface of the NPs. The alkyl chain of coupling agent has a good compatibility with polymer matrix and allows a highly dispersion of $\mathrm{TiO}_{2}$ in organic matrix. For the synthesis of $\mathrm{PEI} / \mathrm{TiO}_{2} \mathrm{BNCs}$, nanoscale $\mathrm{TiO}_{2}$ was dispersed 
in polymer matrix through ultrasonic-irradiation technique. There are some suggestions for interaction of modified NPs with PEI: one offer is that $\mathrm{TiO}_{2}$ was bonded with two oxygen atoms of a carboxylate group via bi-dentate coordination to $\mathrm{Ti}^{+4}$ cation. On the other hand when modified NPs are embedded into PEI with hydroxyl end chains, the $\mathrm{NH}_{2}$ group of coupling agent, which are adsorbed on the surface of $\mathrm{TiO}_{2}$ NPs, can form $\mathrm{H}$-bonding with the hydroxyl groups of PEI as shown in scheme 2 and also unmodified hydroxyl groups of $\mathrm{TiO}_{2}$ can condense with hydroxyl group of PEI chains. Therefore, there are chemical bonds in the interface between $\mathrm{TiO}_{2}$ and PEI chains; consequently, the dispersity of NPs could be greatly improved when compared with PEI without hydroxyl end chains (Mallakpour and Asadi 2012). Interaction of amine with amide group in the side chain and also the formation of $\mathrm{H}$-bond between a carboxylate group and the amine group of coupling agent are other suggestions which can be supposed.

\subsection{Characterization of $\mathrm{PEI} / \mathrm{TiO}_{2} \mathrm{BNCs}$}

The FT-IR spectra of the $\mathrm{TiO}_{2}$, modified $\mathrm{TiO}_{2}$, pure PEI and $\mathrm{PEI} / \mathrm{TiO}_{2} \mathrm{BNCs}$ are shown in figure 2. For unmodified $\mathrm{TiO}_{2}$, the broad peak at $3400 \mathrm{~cm}^{-1}$ corresponds to stretching motions of the surface hydroxyl or the adsorption water and also the broad band observed in the region 540-643 $\mathrm{cm}^{-1}$ corresponds to Ti-O stretching peak. New bands in the FT-IR spectrum of modified $\mathrm{TiO}_{2}$ compared to the unmodified $\mathrm{TiO}_{2}$ (figure $2 \mathrm{~b}$ ) confirmed that the coupling agent was grafted onto the surface of $\mathrm{TiO}_{2}$. In figure 2(b), the bands at $2870-2928 \mathrm{~cm}^{-1}$ can be ascribed to $\mathrm{C}-\mathrm{H}$ symmetrical and asymmetrical stretching absorptions of the $\mathrm{CH}_{2}$ group of the coupling agent, respectively. The newly formed band at 1050

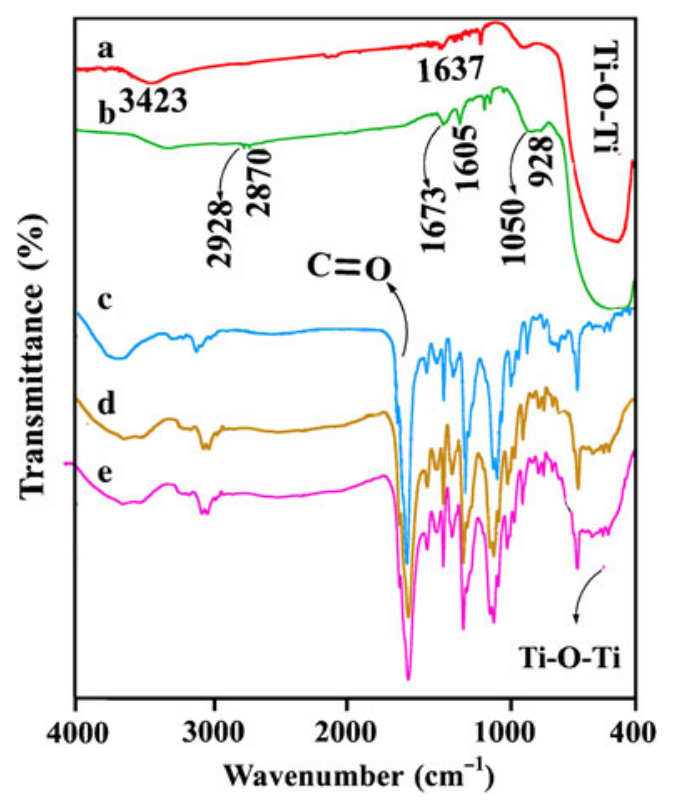

Figure 2. FT-IR (KBr) spectra of (a) $\mathrm{TiO}_{2}$, (b) modified $\mathrm{TiO}_{2}$, (c) pure PEI, (d) $\mathrm{PEI} / \mathrm{TiO}_{2} \mathrm{BNC} 5 \%$ and (e) $\mathrm{PEI} / \mathrm{TiO}_{2} \mathrm{BNC} 10 \%$. and 910-960 $\mathrm{cm}^{-1}$ can be assigned to the stretch vibration of Si-O-Si and Ti-O-Si bonds, respectively. The peak at $1605 \mathrm{~cm}^{-1}$ indicates the presence of the bending vibration of $\mathrm{N}-\mathrm{H}$ bond. In figure 2(c-e), FT-IR spectra of pure PEI and $\mathrm{PEI} / \mathrm{TiO}_{2} \mathrm{BNCs}(5$ and $10 \%$ ) are shown. It is noticed that the $\mathrm{PEI} / \mathrm{TiO}_{2}$ BNCs maintain the features of the pure PEI and modified $\mathrm{TiO}_{2}$. With increasing $\mathrm{TiO}_{2}$ content, intensity of the vibration of Ti-O-Ti group is increased and the intensity of $\mathrm{OH}$ groups of PEI became weaker. This revealed that the $\mathrm{OH}$ groups of PEI chains can react with $\mathrm{NH}_{2}$ and $\mathrm{OH}$ groups of modified $\mathrm{TiO}_{2}$ NPs to form hydrogen and covalent bonds (scheme 2) which could improve the dispersion of $\mathrm{TiO}_{2}$ in PEI chains. These results were also confirmed by XRD analysis.

Morphology of the PEI and $\mathrm{PEI} / \mathrm{TiO}_{2} \mathrm{BNCs}$ were recorded by XRD which is the most frequently used methods to study the structure of BNCs. For hydroxyl end-capped PEI (figure 3), it could be observed that except one crystalline peak, there is a lack of any diffraction peak in the range of $2 \theta$ angle. The diffraction patterns demonstrate the presence of a little proportion of crystalline phase compared to an amorphous one, primarily because of the bulky pendant groups. Furthermore, the amorphous nature of these polymers is also reflected in their good solubility. The XRD pattern of modified $\mathrm{TiO}_{2}$ is in a good agreement with that of standard $\mathrm{TiO}_{2}$ crystallites. It means that the presence of KH550, did not have any great influence on the morphology of NPs. The XRD analysis showed the presence of about $80 \%$ anatase and $20 \%$ rutile phases, which is in agreement with the used commercial $\mathrm{TiO}_{2}$ NPs (Jaleh et al 2011). XRD patterns of $\mathrm{PEI} / \mathrm{TiO}_{2}$ BNCs are suggesting that the samples prepared under the present experimental conditions have crystalline peaks according to the pure $\mathrm{TiO}_{2}$ NPs. The average crystalline size of $\mathrm{TiO}_{2}$ NPs, which has been determined from the half-width of the diffraction using the Debye-Scherrer equation $(D=0.9$ $\lambda / \beta \cos \theta)$ is approximately $15-20 \mathrm{~nm}$, where $D$ is the

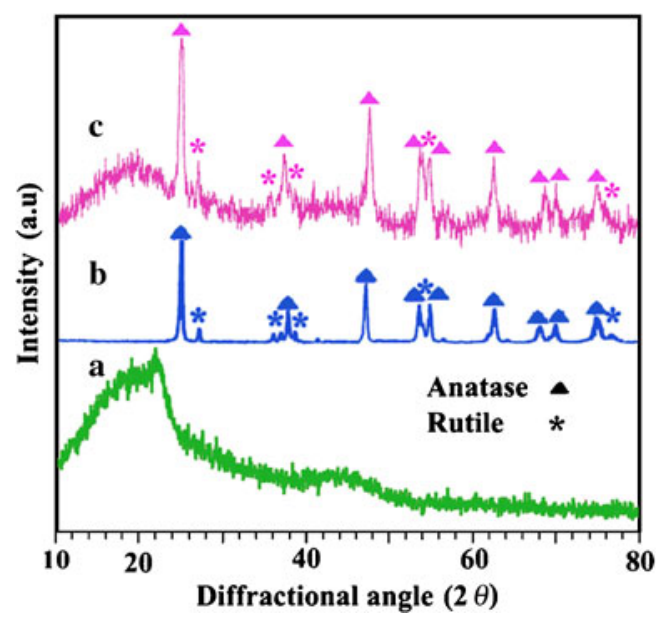

Figure 3. XRD pattern of (a) pure $\mathrm{PEI},(\mathbf{b}) \mathrm{TiO}_{2}$ and (c) $\mathrm{PEI} / \mathrm{TiO}_{2}$ BNC $10 \%$. 


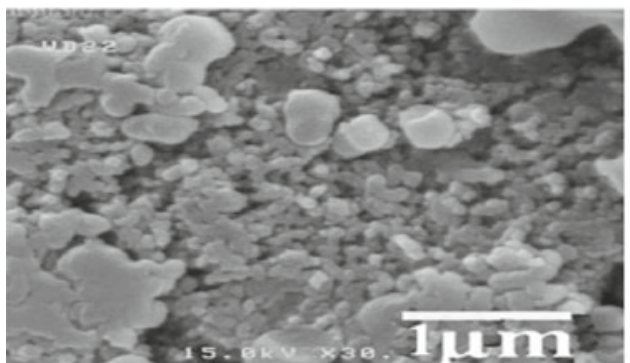

(a)

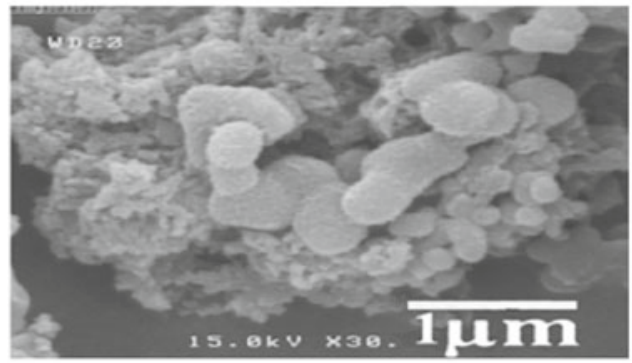

(c)

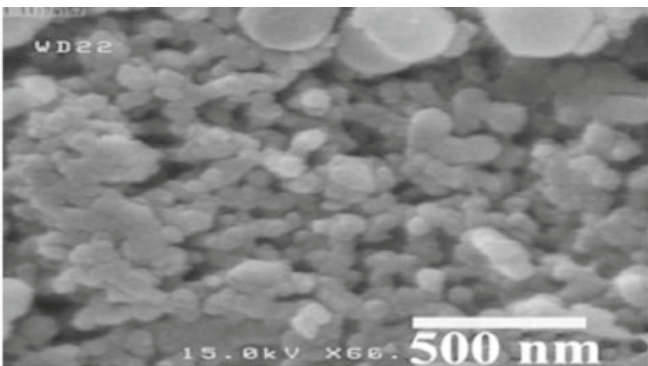

(b)

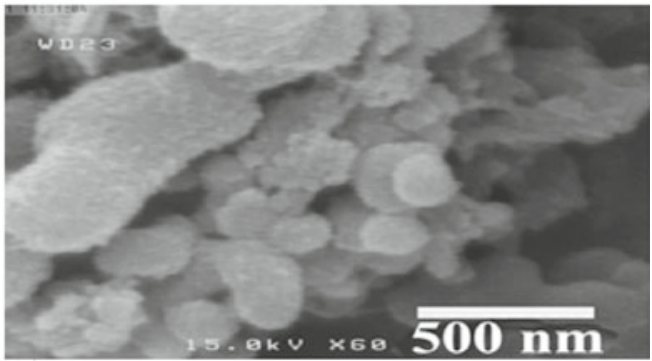

(d)

Figure 4. FE-SEM micrograph of the $\mathrm{PEI} / \mathrm{TiO}_{2} \mathrm{BNC} 5(\mathbf{a}, \mathbf{b})$ and $10 \%(\mathbf{c}, \mathbf{d})$.

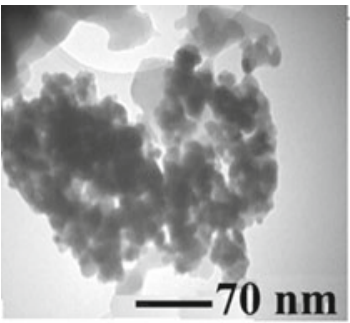

(a)

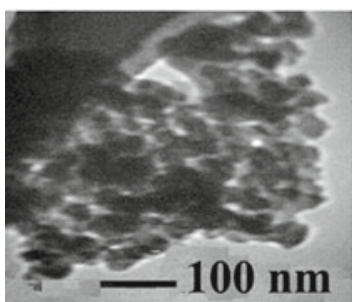

(d)

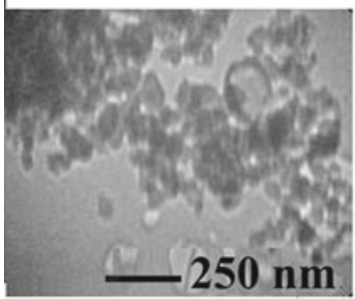

(g)

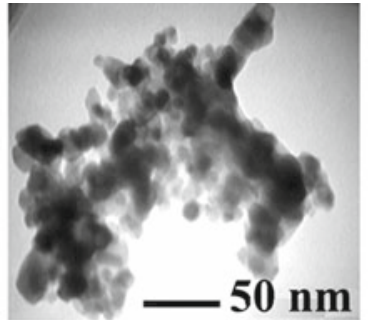

(b)

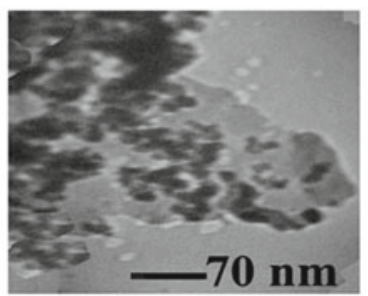

(e)

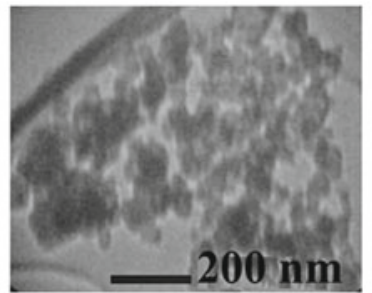

(h)

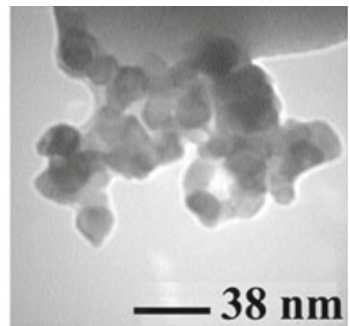

(c)

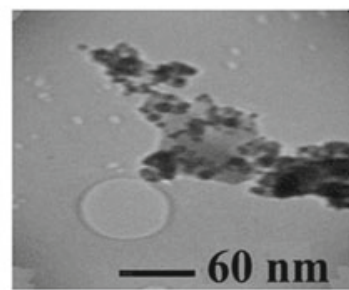

(f)

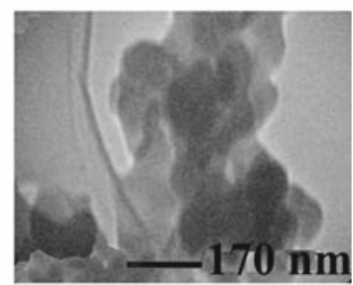

(i)

Figure 5. TEM micrograph of (a-c) the hydroxyl end-capped $\mathrm{PEI} / \mathrm{TiO}_{2} \mathrm{BNC} 5 \%$, (d-f) the hydroxyl end-capped $\mathrm{PEI} / \mathrm{TiO}_{2}$ BNC $10 \%$ and (g-i) $\mathrm{PEI} / \mathrm{TiO}_{2} \mathrm{BNC}_{5} \%$.

crystallite size, $\lambda$ is a wavelength of the radiation, $\theta$ is Bragg's angle and $\beta$ is the full width at half maximum (Kale and Lokhande 2005).
To elucidate the phase morphology of polymers, FE-SEM of $\mathrm{PEI} / \mathrm{TiO}_{2} \mathrm{BNCs}(10$ and $5 \%$ ) are presented in figure 4. Not only any aggregation or phase separation has not been 
observed, but also more uniform distribution of $\mathrm{TiO}_{2}$ on the PEI with hydroxyl end chains is noticeable compared to PEI without hydroxyl end-capped (Mallakpour and Asadi 2012). This shows the PEI with hydroxyl end chains used in this study could make the inorganic part well dispersed into polymer matrix and gave uniform and homogeneous distribution of $\mathrm{TiO}_{2}$ NPs in the resulted BNCs.

TEM has proven to be a powerful tool for studying the dispersion of nanofillers embedded within a polymer matrix and presents the average size of particle found on $\mathrm{TiO}_{2} / \mathrm{PEI}$ samples in more detailed way. Typical TEM images for $\mathrm{PEI} / \mathrm{TiO}_{2}$ (5 and $10 \mathrm{wt} \%$ ) are shown in figure 5(a-f). From these TEM results it is clear that the surface modification of $\mathrm{TiO}_{2}$ NPs will prevent their aggregation and relatively satisfactory dispersion of NPs can be observed. With comparison of these result with TEM images of previous BNC $5 \mathrm{wt} \%$ (PEI without hydroxyl end group), it is clear that the NPs are more disperse and have lower aggregation and therefore smaller particle size (figure 5(g-i) (Mallakpour and Asadi 2012).

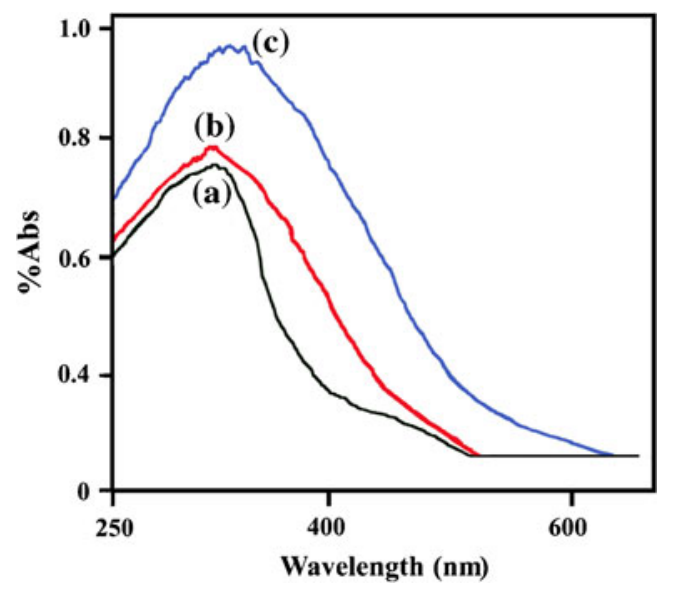

Figure 6. UV-visible absorption spectra of (a) $\mathrm{PEI} / \mathrm{TiO}_{2} \mathrm{BNC}$ $5 \%$, (b) $\mathrm{PEI} / \mathrm{TiO}_{2} \mathrm{BNC} 10 \%$ and (c) pure $\mathrm{TiO}_{2}$.
Figure 6 shows that UV spectra of hydroxyl end-capped PEI $/ \mathrm{TiO}_{2}$ BNC 5 and $10 \%$. It is known that $\mathrm{TiO}_{2}$ is an oxide semiconductor and has an optical bandgap of $385 \mathrm{~nm}$ $(3.2 \mathrm{eV})$. It can be seen that all the samples have absorption below the region of $400 \mathrm{~nm}$. The mechanism of UV absorption in such materials involves the use of photon energy to excite electrons from the valence band to conduction band. The increase in $\mathrm{TiO}_{2}$ NP loadings leads to increased absorption percentage in UV wavelength region. Therefore, the resulting $\mathrm{PEI} / \mathrm{TiO}_{2} \mathrm{BNCs}$ can block out the UV rays, but are transparent to visible light.

\subsection{Thermal analysis}

Thermal stability of polymer nanocomposite as a key factor in determining technological applications and processing conditions usually is studied by TGA. In this study, the thermal properties of the hydroxyl end-capped PEI and $\mathrm{PEI} / \mathrm{TiO}_{2}$ BNCs were evaluated by TGA technique at a heating rate of $20{ }^{\circ} \mathrm{C} / \mathrm{min}$ under $\mathrm{N}_{2}$ atmosphere (figure 7). Thermal stability

Table 1. Thermal properties of the PEI and $\mathrm{PEI} / \mathrm{TiO}_{2} \mathrm{BNCs}$.

\begin{tabular}{lcccc}
\hline & \multicolumn{2}{c}{$\begin{array}{c}\text { Decomposition } \\
\text { temperature }\left({ }^{\circ} \mathrm{C}\right)\end{array}$} & $\begin{array}{c}\text { Char yield } \\
(\%)^{\mathrm{b}}\end{array}$ & LOI $^{\mathrm{c}}$ \\
\cline { 2 - 4 } Polymer & $T_{5}{ }^{\mathrm{a}}$ & $T_{10}{ }^{\mathrm{a}}$ & & \\
\hline $\mathrm{PEI}$ & 350 & 365 & 25.4 & 27.7 \\
$\mathrm{PEI} / \mathrm{TiO}_{2} \mathrm{BNC}(5 \mathrm{wt} \%)$ & 352 & 370 & 31.0 & 29.9 \\
$\mathrm{PEI} / \mathrm{TiO}_{2} \mathrm{BNC}(10 \mathrm{wt} \%)$ & 360 & 390 & 37.9 & 32.6 \\
\hline
\end{tabular}

${ }^{a}$ Temperature at which 5 and $10 \%$ weight loss were recorded by TGA at heating rate of $10^{\circ} \mathrm{C} \mathrm{min}^{-1}$ in a $\mathrm{N}_{2}$ atmosphere.

${ }^{b}$ Weight percent of the material left un-decomposed after TGA at maximum temperature $800{ }^{\circ} \mathrm{C}$ in a $\mathrm{Ar}$ atmosphere.

${ }^{\mathrm{c}}$ Limiting oxygen index (LOI) evaluating at char yield at $800^{\circ} \mathrm{C}$.

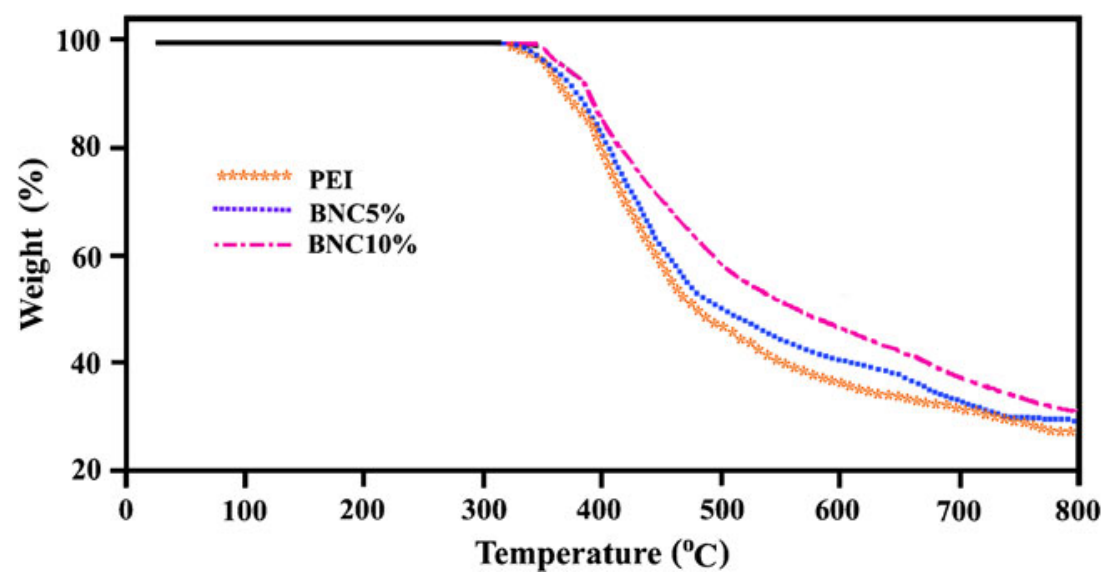

Figure 7. TGA thermograms of $\mathrm{PEI}$ and $\mathrm{PEI} / \mathrm{TiO}_{2} \mathrm{BNCs}$ under $\mathrm{N}_{2}$ atmosphere and a heating rate of $10^{\circ} \mathrm{C} / \mathrm{min}$. 
of these compounds were studied based on 5 and $10 \%$ weight loss $\left(T_{5}, T_{10}\right)$ and residue at $800{ }^{\circ} \mathrm{C}$ (char yield). It is clear that $\mathrm{TiO}_{2}$ NP improves thermal stability due to their thermally stable nature and presence of physical crosslink which restrict the movement of chains. Degradation temperature of the BNCs was slightly increased with $\mathrm{TiO}_{2}$ content. The thermo analyses data are summarized in table 1. Char yield can be applied as decisive factor for estimated limiting oxygen index (LOI) of the polymers based on Van Krevelen and Hoftyzer equation (1976).

$$
\mathrm{LOI}=17 \cdot 5+0 \cdot 4 \mathrm{CR}, \quad \text { where } \mathrm{CR}=\text { char yield }
$$

These $\mathrm{PEI} / \mathrm{TiO}_{2} \mathrm{BNCs}$ with good LOI values which were calculated from their char yield at $800{ }^{\circ} \mathrm{C}$ can be classified as self-extinguishing BNCs. In comparison with our previous work (Mallakpour and Asadi 2012), it is clear that hydroxyl end group did not have any great influence on the degradation temperature of PEI and BNCs.

\section{Conclusions}

Herein we have synthesized new biodegradable and optically active PEI with hydroxyl end chains via polycondensation of chiral diacid with phenolic diol based on amino acids using Vilsmeier adduct as a condensing agent. This thermally stable polymer with good yield and moderate inherent viscosity was used for the preparation of novel $\mathrm{PEI} / \mathrm{TiO}_{2} \mathrm{BNCs}$ via the incorporation of nanoscale $\mathrm{TiO}_{2}$ within polymer matrix by ultrasonication. To obtain uniform dispersion of NP in PEI matrix and to avoid any aggregation, surface of $\mathrm{TiO}_{2}$ NPs were modified with KH550. The characterizations of the BNCs indicate that chemical interaction occurs between the modified inorganic and organic counterpart. Morphology study of resulting $\mathrm{PEI} / \mathrm{TiO}_{2}$ BNCs by FE-SEM and TEM analyses not only showed well dispersed $\mathrm{TiO}_{2}$ NPs in the polymer matrix but also demonstrated hydroxyl function group at the end of polymer chains the reduced the aggregation of NPs and thus lead to a better dispersion of the NP in comparison with PEI without hydroxyl end groups. Finally, combining nano-sized bioactive materials with biopolymer could produce materials with greater bioactivity and better thermal properties. Therefore, because of the existence of both natural amino acid and $\mathrm{TiO}_{2}$ NPs in these novel $\mathrm{BNCs}$, it could be classified under environmentally benign polymers.

\section{Acknowledgements}

We wish to express our gratitude to the Research Affairs Division Isfahan University of Technology (IUT), Isfahan, for partial financial support. Further financial support from National Elite Foundation (NEF), Iran Nanotechnology Initiative Council (INIC) and Centre of Excellency in Sensors and Green Chemistry Research (IUT) is gratefully acknowledged.

\section{References}

Ali B F and Mohan R 2010 Polym. Compos. 311309

Bae T H, Kim I C and Tak T M 2006 J. Membr. Sci. 2751

Bhatta M M, Khushalani D and Satyam P V 2011 Bull. Mater. Sci. 32499

Buzarovska A, Grozdanov A, Avella M, Gentile G and Errico M 2009 J. Appl. Polym. Sci. 1143118

Caseri W 2000 Macromol. Rapid Commun. 21705

Chen J, Zhou Y, Nan Q, Ye X, Sun Y, Zhang F and Wang Z 2007 Eur. Polym. J. $\mathbf{4 3} 4151$

Chen J, Zhou Y M, Nan Q L, Ye X Y, Sun Y Q, Wang Z Q and Zhang S M 2008 Appl. Surf. Sci. 2552244

Cornelissen J J L M, Rowan A E, Nolte R J M and Sommerdijk N A J M 2001 Chem. Rev. 1014039

Feng W, Zhang T R, Liu Y, Lu R, Zhao Y Y, Li T J and Yao J N 2002 J. Solid State Chem. 1691

Ghanshyam L J and Puyam S S 2009 J. Membr. Sci. 328257

Higashi F, Ong C H and Okada Y 1999 J. Polym. Sci. Part A: Polym. Chem. 373625

Itsuno S 2005 Prog. Polym. Sci. 30540

Jaleh B, Shayegani Madad M, Habibi S, Wanichapichart P and Farshchi Tabrizi M 2011 Surf. Coat. Technol. 206947

Joon-Ho O, Lee H, Kim D and Seong T Y 2011 Surf. Coat. Technol. 206185

Kale R B and Lokhande C D 2005 Semicond. Sci. Technol. 201

Koha H C, Parka J S, Jeonga M A, Hwanga H Y, Hongc Y T, Hab S Y and Nama SY 2008 Desalination 233201

Kong Y, Du H, Yang J, Shi D, Wang Y, Zhang Y and Xin W 2002 Desalination 14649

Lee C H, Min K A, Park H B, Hongc Y T, Jung B O and Lee Y M 2007 J. Membr. Sci. $\mathbf{3 0 3} 258$

Li Z and Wang Y 2010 Polym. Compos. 311662

Liaw D J and Liaw B Y 2001 Polymer 42839

Liaw W C and Chen K P 2007 Eur. Polym. J. 432265

Linsebigler A L, Lu G and Yates J T 1995 Chem. Rev. 95735

Mallakpour S and Asadi P 2010 Colloid Polym. Sci. 2881341

Mallakpour S and Asadi P 2012 Polym. Bull. 6853

Mallakpour S and Dinari M 2010 J. Polym. Environ. 18705

Mallakpour S and Dinari M 2011 J. Macromol. Sci. Part A: Pure Appl. Chem. $\mathbf{4 8} 644$

Mallakpour S and Khani M 2007 Polym. Bull. 59587

Mallakpour S and Zadehnazari A 2011 Express Polym. Lett. 5142

Mejia M I, Marin J M, Restrepo G, Rios L A, Pulgarin C and Kiwi J 2010 Appl. Catal. B: Environ. 94166

Narayan H, Alemu H, Macheli L, Sekota M, Thakurdesai M and Gundu Rao T K 2009 Bull. Mater. Sci. 34595

Ray S S, Bandyopadhyay J and Bousmina M 2007 Polym. Degrad. Stab. 92802

Srivastava S, Haridas M and J K Basu 2008 Bull. Mater. Sci. 31 213

Sow C, Riedl B and Blanchet P 2011 J. Coat. Technol. Res. 8 2111

Tomoda K, Ohkoshi T, Nakajima T and Makino K 2008 Colloids Surf. B: Biointerfaces $\mathbf{6 4} 70$

Tryba B, Piszcz M and Morawski A 2009 Int. J. Photoenergy 2009 Article ID 297319, 1

Tsai M H, Chang C J, Chen P J and Ko C J 2008 Thin Solid Films 5165654

Tyan H L, Liu Y C and Wei K H 1999 Polymer 404877 
Valueva S V, Kipper A I, Borovikova L N and Matveeva N A 2010 Russian J. Phys. Chem. A $\mathbf{8 4} 2110$

Van Krevelen D W and Hoftyzer P J 1976 Properties of polymers (New York: Elsevier Scientific Publishing) 3rd ed.

Wang C, Zhang H, Zhang J H, Li M, Sun H and Yang B 2007 J. Phys. Chem. C 1112465
Yang J L, Zhang Z and Zhang H 2005 Compos. Sci. Technol. 65 2374

Yu J C, Ho W, Lin J, Yip H and Wong P 2003 Environ. Sci. Technol. 372296

Yu Y H, Yeh J M, Liou S J and Chang Y P 2004 Acta Mater. 52475 Zhang W and Huang Y 2011 J. Polym. Environ. 19177 